\title{
Strategic marketing of cigarettes to young people in Sri Lanka: "Go ahead-I want to see you smoke it now"
}

We entered the disco at about midnight. Within a minute, a "golden girl" approached me, holding out a box of Benson $\mathcal{E}$ Hedges: "Here, take one". I took it. She extended her hand again, this time holding a small glowing orb-a cigarette lighter, I soon realised. I balked; she encouraged me: "Go ahead - I want to see you smoke it now". I told her I thought it would make me cough. "No, these are smoother, not so strong" she reassured me. "I want to see you smoke it now." I put the cigarette in my pocket.

Tamsyn Seimon, notes taken at the Golden Tones Disco, Nuwara Eliya, Sri Lanka, April 1997

Facing an intensifying anti-tobacco climate within the United States and Europe, British American Tobacco (BAT), like other multinational tobacco corporations, has shifted its focus to the vast markets of developing countries. In the small island nation of Sri Lanka, BAT's subsidiary Ceylon Tobacco Company (CTC) uses discos, music shows, free giveaways, powerboat races, attractive employment packages, and other pointed measures to draw smokers. Exuding the essence of "the good life"-in perverse denial of the prevailing somber mood in Sri Lankathese lavish campaigns target the country's most vulnerable groups, preying especially upon the young and a vast, untapped female population.

\section{Background}

Situated off the southeastern tip of India, Sri Lanka has done well for a south Asian country. Despite an annual per capita gross national product (GNP) of less than US $\$ 750$, Sri Lanka exhibits impressive health indicators, more like those of far wealthier nations: very high life expectancy, low infant mortality, and high male and female literacy. (The 1996 World Bank statistics from the world wide web in June 1998 show the following comparisons. GNP per capita (US\$): Sri Lanka, 740; United States, 28 020; India, 380. Life expectancy at birth (years): Sri Lanka, 73; United States, 77; India 63. Infant mortality (per 1000 live births): Sri Lanka, 15; United States, 7; India, 65. Illiteracy (\% of population age $15+$ ): Sri Lanka, 10; United States, not available; India, 48.)

Although smoking prevalence among middle-aged men is high (roughly 55\%), rates among younger men have declined in recent years. Fewer than $1 \%$ of Sri Lankan women smoke; only Afghanistan has a lower women's smoking rate.

Despite these promising statistics, daily life for Sri Lankans is difficult. Since 1983, the country has been locked in civil war, draining the economy and constraining individual potential. At least 55000 people are reported to have been killed in the war to date; this statistic is surpassed by the number of suicides during the same period-Sri Lanka's suicide rate is second highest in the world. ${ }^{1}$ For many young people, the military is the only employment option: full-time jobs are in scant supply, even for those with advanced qualifications and education. (Figures released by the Sri Lanka Department of Census and Statistics on 27 June 1998 show a decline in Sri Lanka's unemployment rate from $13.1 \%$ in 1994 to $10.3 \%$ in 1997. However, more than $80 \%$ of the unemployed are aged 18-29, and unemployment is highest among those with the General Certificate of Education (Ordinary Level), a high-school degree.)

\section{Contests, features, and radio shows}

Sri Lanka's unemployed youth spend their days looking for work, playing sports, and watching television. Eager to tap this latent consumer pool, CTC uses images of fun-filled, adventurous, affluent "Western lifestyles" in promoting its premium and elite brands. (CTC's major cigarette brands are Bristol (the popular brand), John Player Gold Leaf (the premium brand), and Benson \& Hedges (the elite, upmarket brand).) Recent campaigns for Players Gold Leaf cigarettes, for example, feature huge billboards depicting rugged sailors on gorgeous ocean-going yachts, with a skyscraper skyline in the background. Posters from the same series are found in thousands of restaurants and snack shops, including those frequented primarily by schoolchildren (figure 1).

Periodically, CTC holds contests"cigarette purchase required for participation"-promising exciting trips to international sports events for a lucky few. One such contest offered a grand prize trip to Abu Dhabi to attend the "World Championship Challenge F1 Powerboat Race". Most contestants won a free cigarette.

Benson \& Hedges targets a more exclusive audience-the country's English speaking youth-through "Golden Tone News", a weekly pop music supplement published in an English language newspaper. This supplement 


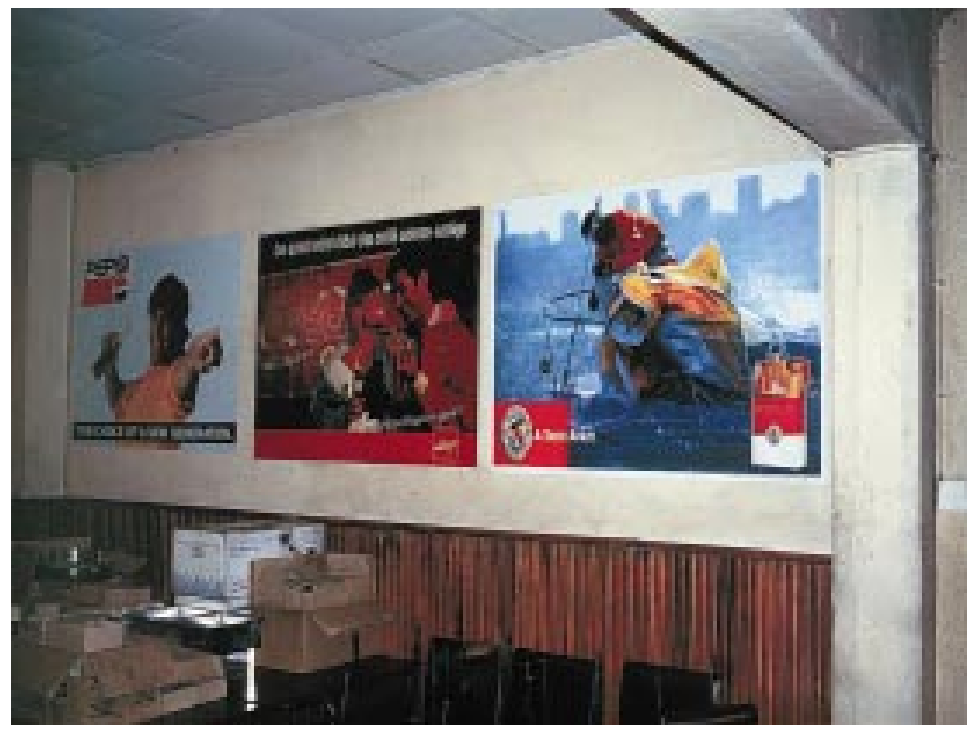

Figure 1 A Gold Leaf cigarette poster on the wall at "Candy Corner". This snack shop is situated adjacent to Trinity College, one of Sri Lanka's preeminent boys' schools.

includes lyrics from international hit songs, interviews with popular artists, and announcements of upcoming entertainment events. It also features bright advertisements for Benson \& Hedges cigarettes, with the motto "Turn to Gold".

During the holiday season of December 1997, Benson \& Hedges launched the "Gold Rush", advertised on the radio, in newspapers, and at points of sale. Despite a ban on cigarette advertising on the radio, CTC sponsored heavy radio publicity-without the mention of cigarettes per se-on YES-FM, the Englishlanguage radio station that caters to trendy, Western-influenced youth. Amid the multitude of commercials for cellphones, credit cards, and imported powdered milk, YES-FM's American-sounding disc jockeys played the "Turn to Gold" advertisement, featuring a male announcer reminiscent of those for automobile commercials on American television, and a female backup singer:

Singer: "Turn turn, Turn to Gold."

Announcer: "Don't miss out on a golden opportunity this season."

Singer: "Turn turn, Turn to Gold."

Announcer: "Join the Gold Rush at any leading supermarket."

Singer: "Turn turn, Turn to Gold."

Announcer: "And take home some fantastic golden gifts."

Singer: "Turn turn, Turn to Gold."

Announcer: "Bottle opener key tags, clocks, watches, and AM/FM radios. All you've got to do is rush to your supermarket and then you've..."

Singer: "Got to Turn to Gold!"

Announcer: "See newspapers for details."

The complementary newspaper "details" include full-colour photos of the available "gifts", alongside Benson \& Hedges advertisements (figure 2). YES-FM does not cater only to youth in their teens, twenties, and thirties. They also have a loyal, lower-middle school audience of English-speaking Sri Lankans, who

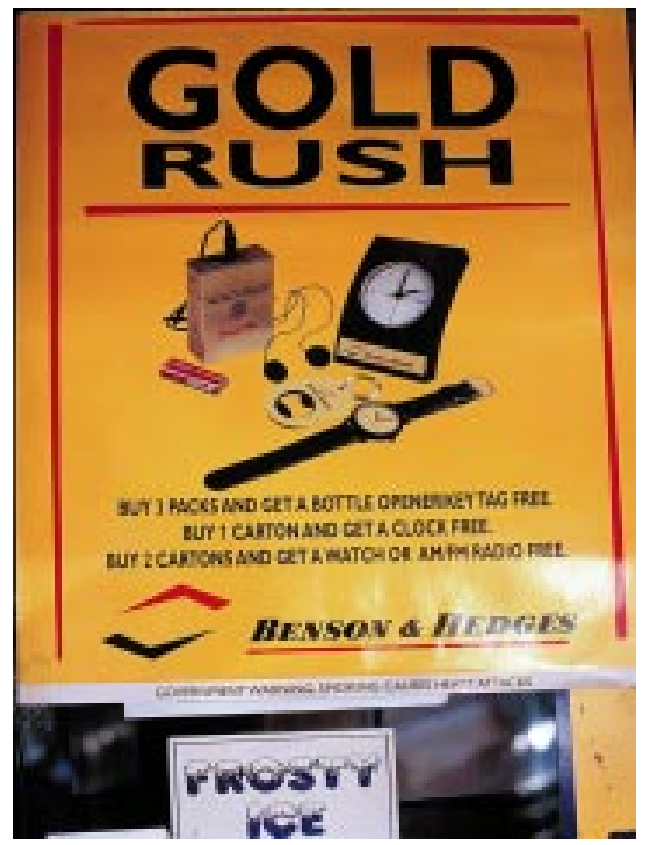

Figure 2 Gold Rush merchandise poster displayed in the window of a "leading supermarket".

participate actively in weekly call-in shows such as "Junior Joy", which caters to 4-10 year olds.

\section{Targeting girls}

Sri Lankan women conform to a strict, culturally defined, non-smoking norm. Among the few Sri Lankan women who do smoke, there are two main categories: elderly women in villages, who generally smoke suruTTu (cigars) for perceived medicinal purposes; and young, trendy, Westernised urban women, who smoke cigarettes. CTC is working aggressively to broaden its appeal, aiming for the $99 \%$ of women who do not yet smoke.

The Benson \& Hedges "Golden Tones Disco", held in the luxurious Grand Hotel in Nuwara Eliya, appears to have been devised to entice young people, and girls in particular, to smoke. A former hill station used by the British to escape the heat of Sri Lanka's coastal regions, Nuwara Eliya is invaded by urban elite every April-"the season"-for a month of revelry marked by conspicuous consumption. CTC's presence is ubiquitous: from the billboard (figure 3) announcing the month's activities-such as "School band display", "Carnival", "Helthy [sic] child contest", "Mahagastota hill climb", and "Agriculture exhibition"- to the centrally located John Player Gold Leaf cigarette booths (figures 4 and 5), and the Benson \& Hedges discos.

We attended the disco for a first-hand look at CTC's activities. "Golden girls" clad in shimmering, gold-coloured saris and gold platform shoes appeared to have been instructed to greet every woman who entered, with the goal of getting them to smoke a cigarette. The aggressive promotion continued throughout the night:

Glowing "Benson \& Hedges" and "Golden Tones" light boxes festooned the walls. The dance floor played host to a fantastic laser-light show, in 


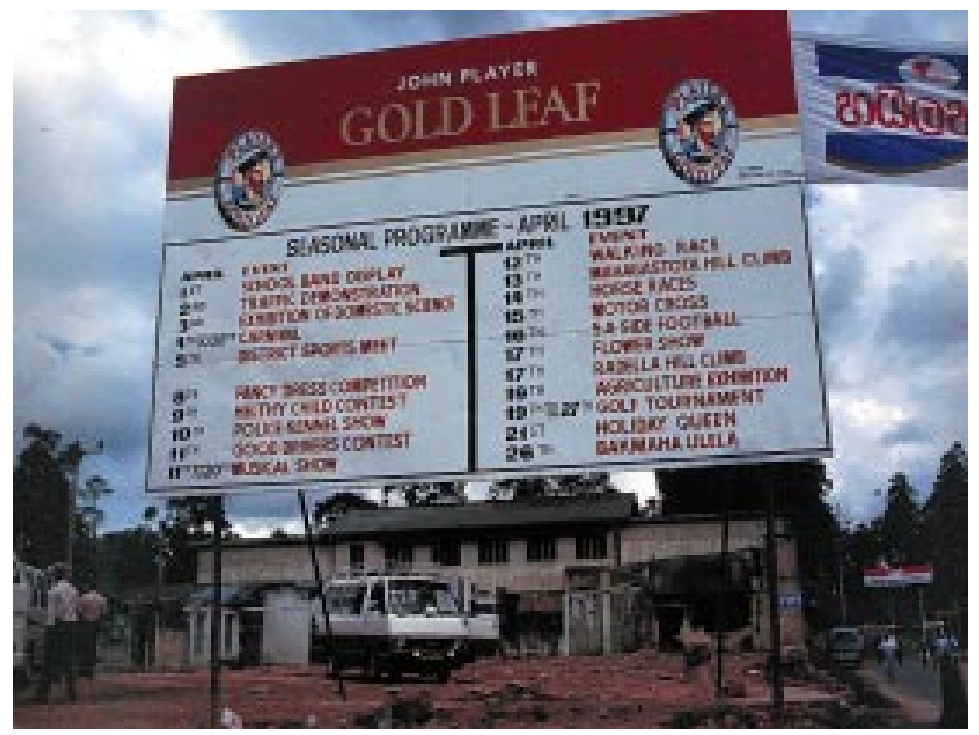

Figure 3 Billboard announcing activities for "the season", Nuwara Eliya, Sri Lanka.

which the words "Benson $\mathcal{E}$ Hedges" were "written" onto the wall by the laser beam, amid an impressive array of gyrating stick figures. Drinks and cigarettes were available from one corner. The music, a string of "top ten" dance hits from the West, was frequently interrupted by "prize" drawings: if the number on your ticket stub was called, you won a special gift. Only boys could win the bright yellow Benson Eo Hedges keyrings, shirts, and caps, since girls held no tickets; admission for boys was Rs 250 [about US $\$ 4.50$, a couple of days' wages for the average Sri Lankan], free for girls.

Tamsyn Seimon, notes taken at the Golden Tones Disco, April 1997

We have no photographs of the interior of the disco. As soon as we took out our still and video cameras, we were approached by "bouncers" stating that this was a "private, sponsored event ... no photographs allowed".

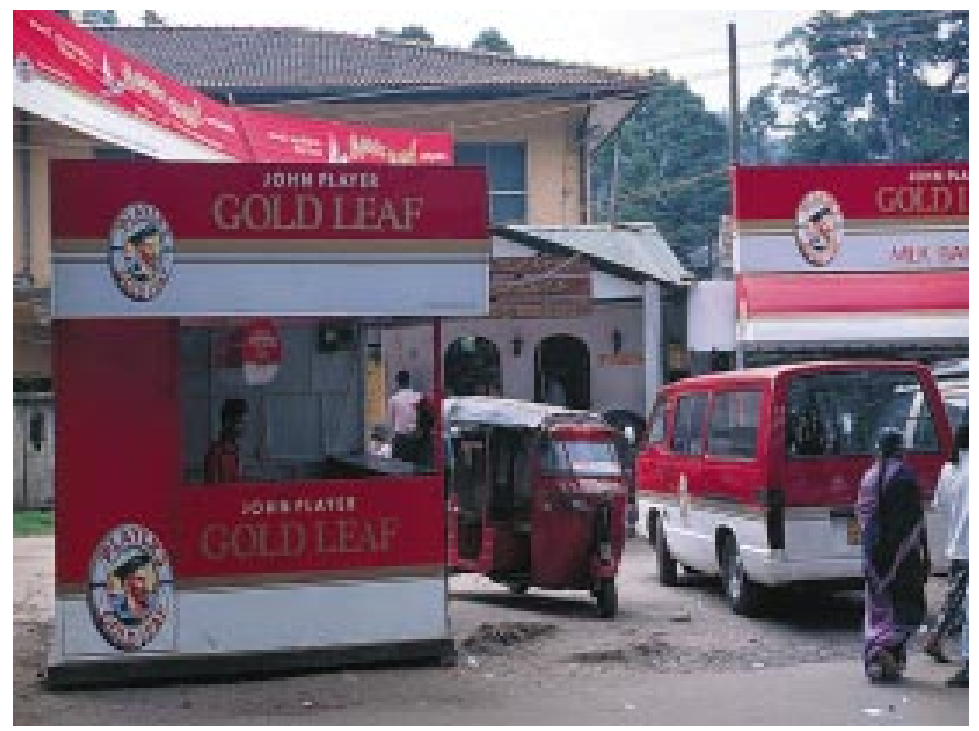

Figure 4 Fohn Player Gold Leaf cigarette booths, a "Milk Bar", and vehicles in Nuwara Eliya during "the season".
They made an exception for two video camera operators, who were "hired by us" (that is, CTC).

CTC does not restrict its promotional activities to special events. In Kandy, Sri Lanka's second largest city, CTC takes a subliminal approach, associating its familiar logo with a campaign for child safety. The front wall of the prestigious "Girls High School", situated along the main road connecting Kandy with the capital, Colombo, is painted with the logo of CTC's insurance wing, CTC Eagle, and the words, "GIRLS HIGH SCHOOL CAR PARK". Next to the logo, "CTC Eagle" is written in Sinhala, the language of the majority of Sri Lankans, along with a statement (in Sinhala) that "Children who walk on the right side of the road are good children" (figure 6). The road is heavily trafficked by vehicles and pedestrians, including thousands of schoolchildren of all ages. The CTC Eagle message imparts a sense of security and caring in the midst of danger: at least two children have died while crossing that road. (CTC Eagle is itself an example of the tobacco industry associating itself with something reassuring and nurturing, in this case, life insurance.)

In a more blatant marketing strategy, CTC engages groups of well-paid girls to "hang out" at popular Colombo shopping malls, on university campuses, and on the more exclusive "intercity" trains, distributing free merchandise. Likewise, CTC employs young women in their 20 s to drive around in bright red "Players Gold Leaf" cars and jeeps, handing out free cigarette samples and promotional items. The spectacle of young women driving these vehicles draws tremendous attention; the free cigarettes, hats, shirts, lighters, and

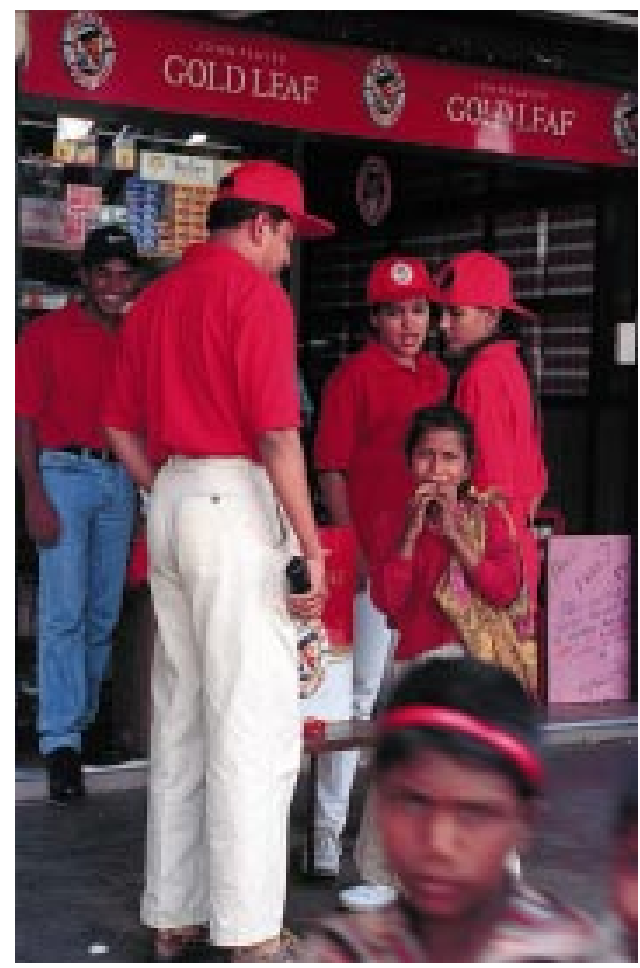

Figure 5 Models promoting Gold Leaf cigarettes during "the season" in Nuwara Eliya. 


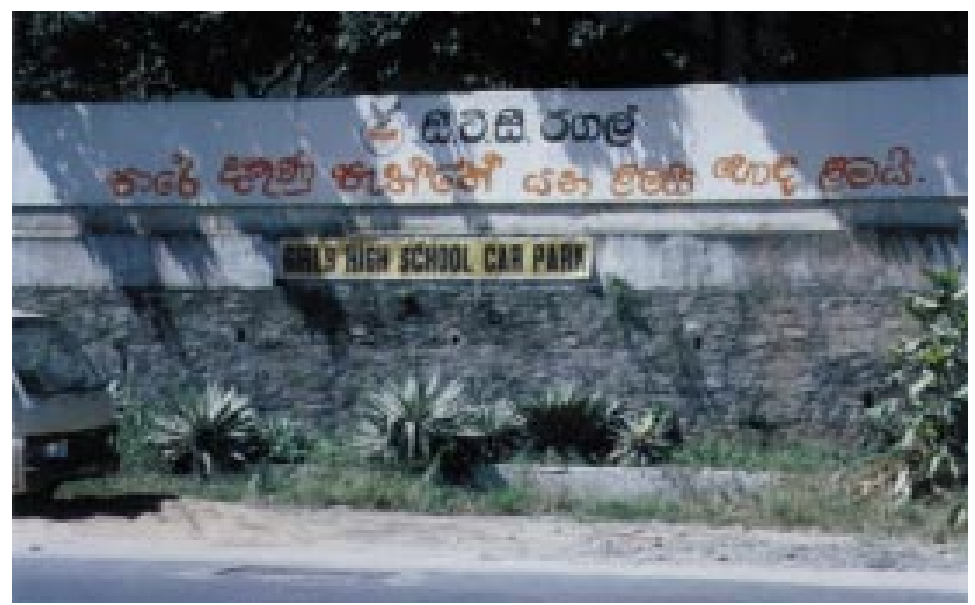

Figure 6 The Ceylon Tobacco Company's Eagle Insurance sponsoring a message about child safety.

keychains extend the promotion well beyond the event.

\section{Job recruitment}

Perhaps the most flagrant marketing of a cigarette culture to Sri Lankan youth takes the form of recruitment packages for university graduates. Average graduates of a Sri Lankan university might expect to earn roughly Rs5000 per month (about US\$81) for a full-time job, if they are fortunate to find a position at all. In its recruitment drives at universities, CTC distributes a slick, expensively produced information package-printed in the United Kingdom by BAT - that oozes with a sense of wealth and prosperity. A job offer from CTC is hard to refuse, no matter how one feels about smoking.

A case in point: a Kandy-based drug prevention youth group held a car wash to raise money. One of their clients during the day turned out to be a CTC employee, who was amused when he learned they were raising money for the LIFE drug prevention movement. He challenged one volunteer: "If I offered you a job right now, for Rs25 000 per month, would you take it?" Without a moment's hesitation, the volunteer said that yes, of course he would. LIFE's staff is entirely volunteer, except for two positions, paid

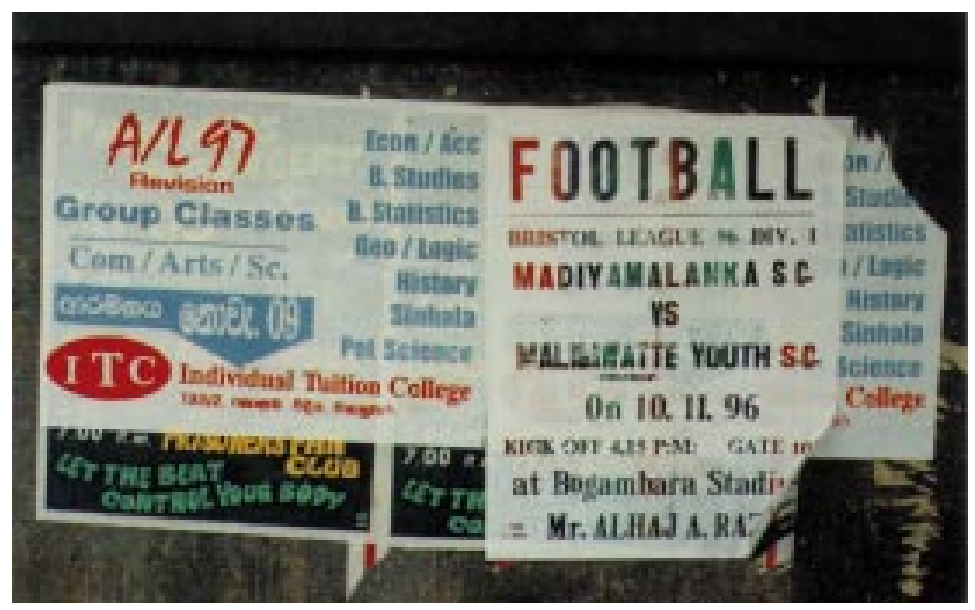

Figure 7 Poster announcing a CTC-sponsored Bristol League football (soccer) match.
Rs3000 and Rs2000 per month. They know they would be foolish to turn down a "big job".

\section{CTC influence}

Ample finances have ensured CTC's ability to infiltrate most domains of Sri Lankan life. Prominent sports, political, and business figures have, at key moments, been supportive of CTC, and indifferent to public sentiment critical of the tobacco industry.

Probably the most desired "big job" for any Sri Lankan boy is to be a champion cricket player-a connection that CTC exploits vigorously. Children of all income levels play cricket whenever and wherever possible, from paddy fields to dusty streets. Members of the Sri Lankan World Cup championship team (the country holds the one-day test cricket World Cup title) are revered more than film stars, celebrities, and politicians-local or international. When CTC introduced Benson \& Hedges cigarettes to Sri Lanka in 1996, the launching took place in Australia during a televised cricket match, deftly circumventing Sri Lanka's prohibition of cigarette advertising on television. Soon thereafter, the former vice-captain of the Sri Lankan cricket team became a prominent executive for Benson \& Hedges.

CTC sponsors many other sporting events under the banner of Bristol, a brand so popular its name is virtually synonymous with "cigarette". The island-wide "Bristol League" (figure 7) and "Bristol FA" Cup football (soccer) tournaments, for example, attract the participation of thousands of youngsters throughout the year. These extremely popular events are accompanied by posters and athletic jerseys bearing CTC product names.

The "Bristol Tour-de-Lanka" is a gruelling bicycle race that passes through most regions of the island, drawing crowds of onlookers along its course. The volunteers of the LIFE drug prevention movement launched a campaign to protest the "cancer race" when it came through their area. Their hand-painted posters were torn down, however, as fast as they could paste them up; some posters were actually seized and burned. When LIFE reported the harassment to the police, they received sympathy, but were told the police had instructions not to follow up on such complaints during the bike race. A senior police officer had been the guest of honour at the ribbon-cutting ceremony inaugurating the race.

At the local level, CTC sponsors the cricket ground scoreboard at Trinity College, an exclusive school for boys. When boys belonging to the school "drug prevention club" resolved to identify an alternate sponsor for the scoreboard, CTC matched or surpassed all other sponsors' bids. The school ended up retaining the CTC sponsorship.

Likewise, CTC intervened when the LIFE youth group secured commercial sponsors for anti-smoking banners during the Kandy Esala Perahera. Tens of thousands of Sri Lankans attend this annual, two-week Buddhist festival, which culminates in daily processions of 


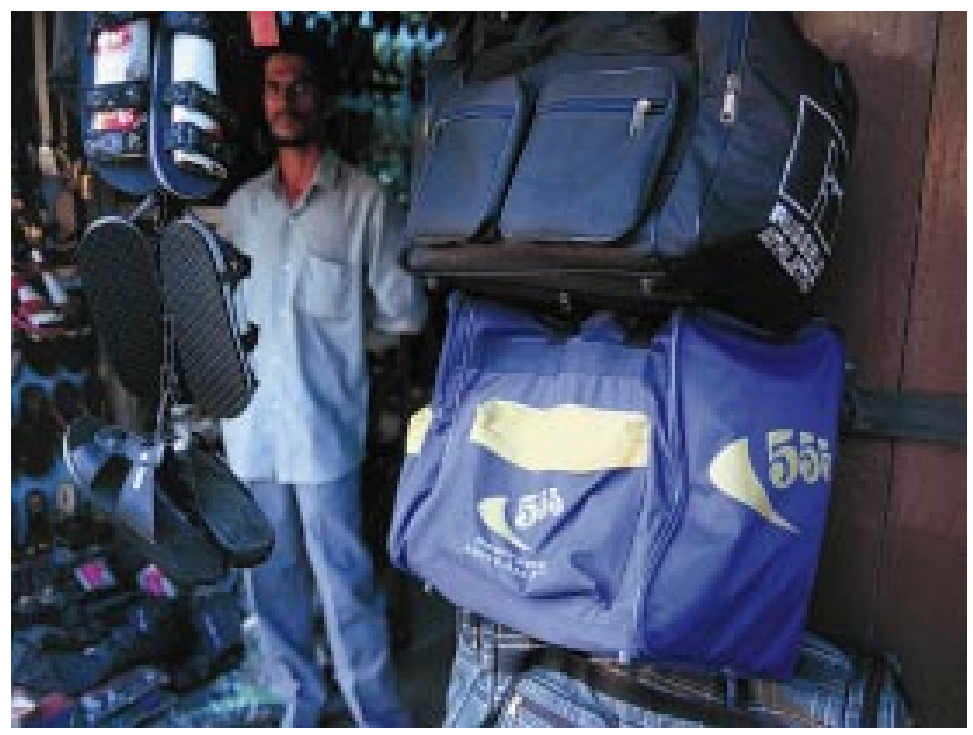

Figure 8 Imported brand merchandise available in the marketplace.

elephants, musicians, and dancers through the streets of Kandy. During the August 1997 Perahera, nine of 15 anti-smoking banners "disappeared" from street locations throughout the city. Later, two of the corporate sponsors notified the youth group that they had received telephone calls from CTC officers voicing grave disappointment at their decision to sponsor anti-smoking materials. The CTC officers apparently went on to stress the importance of local businesses looking out for each others' interests.

\section{A new era for CTC?}

Recently, Sri Lanka's government announced sweeping legislative changes which would have included a ban on tobacco advertising beginning on 1 January 1999. At the time of going to press, only certain parts of the advertising ban have come into effect as the Act has not yet been presented to parliament. The success of this strategy will depend on strict enforcement, and the ability of the tobacco control community to preempt a surge in indirect advertising. Failure to do so will enable
CTC's allure to linger in the cultural subconscious well beyond implementation of the ban.

For CTC, the experience of BAT subsidiaries in other countries provides a useful precedent. Confronted with similarly strong legislation, tobacco companies in Malaysia, Singapore, and Thailand have found ways to circumvent restrictions, promoting their products innovatively to ensure their longevity. Through "brand-stretching"-marketing coffee, music, clothing, footwear, luggage, and other items under the brand names of familiar tobacco products - the tobacco companies have retained and extended brand visibility, without breaking the law. Even now, teeshirts, bags, boots, and other merchandise sporting international cigarette logos are available at markets and shops in Sri Lanka (figure 8).

Ample finances and years of unrestrained tobacco advertising have enabled CTC to infiltrate Sri Lankan society with messages and images associating smoking with wealth and carefree living. It is critical for Sri Lanka's tobacco control community to expose and undermine this legacy, proclaiming instead the direct connection of the industry and its products to poverty and illness. With the support of an advertising ban, proactive measures at the governmental and grass roots levels might offer Sri Lanka's impressionable youth a reprieve from the illusory lure of a smoking lifestyle. Garrett Mehl would like to acknowledge the United States
Educational Foundation of Sri Lanka, which supported this Educational Foundation of Sri
study through a Fulbright Grant. study through a Fulbright Grant.

TAMSYN SEIMON The Sri Lanka UNICEF Child Mental Health Programme; tamusana@welchlink.welch.jhu.edu

GARRETT L MEHL Center for International Community-based Health Research, fohns Hopkins University School of Hygiene and Public Health, 615 North Wolfe Street,

Baltimore, Maryland 21205, USA; gmehl@welchlink.welch.jhu.edu

Correspondence to Dr Mehl

1 La Vecchia C, Lucchini F, Levi F. Worldwide trends in suicide mortality, 1955-1989. Acta Psychiatr Scand 1994; 